\title{
CASTRACIÓN QUÍMICA Y DETERMINISMO *
}

\author{
Josep M. Vilajosana ** \\ Universidad Pompeu Fabra
}

RESUMEN. En este trabajo se plantea el desafío que el determinismo puede plantear a la justificación de la pena en los casos de los violadores compulsivos. Ello se hace poniendo de relieve las relaciones que existen entre las respuestas a las preguntas siguientes: ¿por qué castigar?, ¿cuánto castigar?, ¿a quién castigar?, ¿cómo castigar? Se muestra que respecto a los posibles objetivos de la pena (¿por qué castigar?), sólo cabe una justificación basada en la incapacitación, pero esto supone no poder justificar un tiempo determinado de imposición de pena (¿cuánto castigar?). El examen del problema del determinismo, por su lado, muestra que no podemos prescindir del retribucionismo en la distribución (¿a quién castigar?). Todo lo anterior llevará, por último, a formular un dilema respecto a la llamada «castración química» (¿cómo castigar?).

\footnotetext{
Palabras clave: justificación de la pena, retribucionismo, determinismo, castración química.
}

ABSTRACT. This paper analyzes the challenge that determinism brings to the justification of punishment in the cases of the compulsive rapists. This is made by showing the relations that exist among the answers to the following questions: why to punish?, how much to punish?, to whom?, how to punish? It is held that with respect to the possible goals of punishment (the why of punishment), there is only a justification based on the incapacitation, but this implies not being able to justify a determinate time of imposition of punishment (the how much to punish). The examination of the problem of determinism, in turn, shows that we can not do without retribution in the distribution (to whom can we punish?). This analysis will lead, finally, to formulating a dilemma with respect to the possibility to impose «chemical castration» as a punishment (the how of punishment). tion.

Keywords: justification of punishment, retributionism, determinism, chemical castra-

* Fecha de recepción: 28 de abril de 2008. Fecha de aceptación: 22 de mayo de 2008.

** Presenté una versión anterior de este trabajo en una conferencia pronunciada en la Universidad Carlos III el día 15 de diciembre de 2007. Agradezco las observaciones de los participantes, en especial las de los profesores J. DOPICO, R. EsCUDERO y J. GONZÁLEZ AMUCHASTEGUI. 


\section{ALGUNOS INTERROGANTES SOBRE LA JUSTIFICACIÓN DE LA PENA}

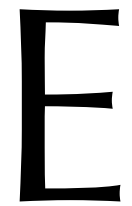

120 de agosto de 2007 el presidente francés, Nicolas Sarkozy, anunció medidas más duras contra los pederastas, como la creación de un hospital especial para ellos al que deberán ir obligatoriamente y aseguró que ninguno lo abandonará hasta que un comité de médicos dictamine que han sido curados. Sarkozy también se mostró favorable a la castración química de los pederastas. El Gobierno francés reaccionaba así después de que un hombre condenado en tres ocasiones por abusos sexuales a menores reincidiera con un niño de cinco años al que mantuvo secuestrado durante varios días. El jefe del Estado francés afirmó que los delincuentes sexuales sólo saldrán de prisión cuando hayan cumplido su pena, sin posibilidad de reducción, y tras un examen de su peligrosidad por un comité médico. El tratamiento será de tipo hormonal o «castración química», dijo Sarkozy, quien empleó un lenguaje firme: «No se puede dejar en libertad a depredadores, a gentes que pueden matar y destrozar la vida de niños» (La Vanguardia, 20 de agosto de 2007).

Por su lado, en España, un editorial de El País titulado «Violadores de riesgo», escrito después de la puesta en libertad del llamado violador de la Valle Hebrón, nos recordaba «que la cuestión de fondo es qué hacer con éste y con otros violadores patológicos una vez han cumplido condena, salvo que se reclame para ellos no ya la cadena perpetua, que tiene un término, sino la prisión de por vida. Pero entre esta medida aberrante e inconstitucional, que supondría una especie de condena a muerte en vida, y la puesta en libertad sin más, existen posibilidades de actuación tanto en el terreno policial como en el médico-sanitario, sin olvidar el judicial. Unas medidas que deben adoptarse con discreción, prudencia y determinación, evitando presentar alguna de ellas como la panacea; tal es el caso de la castración química. Esta medida adquirió notoriedad hace una docena de años a raíz del caso de un condenado en EE.UU. que solicitó la conmutación de condena a cambio de su castración. Así se hizo, pero meses después violó con un palo a una mujer, asesinándola. A veces, el remedio suele ser peor que la enfermedad» (El País, 24 de septiembre de 2007).

Estos ejemplos notorios, referidos a casos de delitos sexuales cometidos por delincuentes reincidentes, ponen en marcha inmediatamente mecanismos de reformas de las leyes penales para intentar atajar de algún modo la alarma social que generan. Así ocurrió en Francia y así está ocurriendo en España. Pero en el momento de poner en práctica tales reformas nos deberían asaltar algunas dudas: ¿Está justificado moralmente que a alguien que ha cumplido condena se le imponga alguna medida posterior? ¿Es posible mantener que la finalidad de la pena es la rehabilitación frente a delincuentes que no quieren o no pueden ser rehabilitados? ¿Es compatible la imposición de penas como retribución de actos delictivos cuando su realización escapa al control del delincuente? Afrontar estos y otros problemas semejantes de forma rigurosa exige antes tomar conciencia de cuáles son las razones que pueden justificar moralmente la imposición de penas a quien ha cometido un delito.

Siguiendo a HART, podemos entender por «pena» un acto que ocasiona un daño, impuesto como consecuencia del incumplimiento de una norma jurídica, que se inflige al responsable del incumplimiento, es administrado intencionadamente por seres hu- 
manos distintos a la víctima, y cuya imposición y regulación vienen determinadas por el sistema jurídico, cuyas normas han sido incumplidas (HART, 1968: 5).

Toda sociedad que imponga este tipo de castigos debe justificarlos, por cuanto suponen la acción del Estado a la hora de ocasionar de manera intencionada un daño. Dañar a una persona es, prima facie, moralmente incorrecto. Es decir, lo es a menos que exista alguna justificación satisfactoria. La pregunta que nos podemos formular ahora es la siguiente: ¿`se pueden ofrecer razones de carácter general para castigar legalmente a las personas?

Antes de responder a este interrogante, sin embargo, hay que advertir que en él se esconden en realidad al menos cuatro preguntas distintas:

1. ¿Por qué castigar? Esta cuestión hace referencia a los objetivos y aspiraciones que se pretende alcanzar con el castigo institucionalizado.

2. ¿Cuánto castigar? Aunque se esté de acuerdo respecto al objetivo u objetivos que la pena debe cumplir para estar justificada, hay que inquirir acerca de qué medida del castigo está justificada. ¿Hay que respetar algún principio de proporcionalidad? Ante dos delitos iguales, ¿hay que castigar con las mismas penas?

3. ¿A quién castigar? Este interrogante tiene que ver con la clase de los destinatarios del castigo. ¿Pueden serlo todas las personas o sólo las que posean ciertas características?

4. ¿Cómo castigar? Esta pregunta atañe al tipo de pena que se considera justificada y al modo de su implementación.

En ocasiones en los debates acerca de la justificación de la pena, estas cuestiones se hallan mezcladas. Tal vez ello se deba a que las respuestas a estas preguntas no son independientes, de tal modo que, para ser consecuente, al responder de una determinada manera a uno de estos interrogantes hay que responder también de una forma precisa a otros. Pero el hecho de que efectivamente existan estas relaciones entre los problemas no autoriza a mezclarlos. Por el contrario, lo que hay que hacer es mostrar cuáles son esas relaciones y ser consecuente con las respuestas.

En lo que sigue, intentaré poner de relieve algunas de estas relaciones, teniendo en cuenta principalmente los retos que plantean a la justificación de la pena la existencia de delitos cometidos por individuos como los violadores compulsivos y la posibilidad de que sea cierto el determinismo.

\section{OBJETIVOS DE LA PENA}

Los objetivos que se suelen perseguir a través del establecimiento de sanciones pueden resumirse en cuatro: retribuir, disuadir, incapacitar y rehabilitar (a veces, se apunta como un quinto objetivo el carácter simbólico de la pena, pero aquí no me voy a ocupar de éste). Es difícil encontrar un sistema jurídico, cuyas sanciones estén diseñadas para cumplir únicamente una de estas aspiraciones, ya que normalmente se hallan mezcladas. Esta circunstancia, por un lado, resulta inevitable, dadas algunas conexiones entre ellas. Por ejemplo, cuando se castiga a un ladrón con una determinada pena, se le «retribuye» por su acto, al tiempo que el castigo sirve de disuasión para que otros no cometan actos parecidos. Por otro lado, esta superposición de objetivos suele ser fuen- 
te de problemas importantes cuando alguien intenta justificar las penas en nuestros sistemas jurídicos contemporáneos, como después se verá. Ahora es momento de analizar aunque sea brevemente cada uno de estos objetivos. La mayor parte de lo que diré en este apartado es conocido, pero únicamente quiero subrayar lo que considero relevante para responder a las preguntas anteriormente planteadas.

\subsection{Retribuir}

Ésta seguramente es la forma más antigua de justificar el castigo. Ya en el Código de Hammurabi aparecía la fórmula conocida de «ojo por ojo, diente por diente». Se encuentra también en la Biblia y se puede hallar en el Derecho romano bajo la figura de la ley del talión.

Lo primero que hay que decir es que la retribución se orienta al pasado. Pensamos en retribuir a alguien por un acto (acción u omisión) que ya ha tenido lugar. En un primer momento la idea de la retribución podría provenir de los instintos de venganza. Pero esto deja de tener sentido cuando quien impone la pena, como dije antes, es una institución, distinta de la víctima.

KANT fue un defensor a ultranza del retribucionismo. Para él, retribuir el castigo es el único objetivo moralmente valioso de la pena. Por eso, la retribución excluiría las otras posibles formas de justificación. El castigo, nos dice KANT, nunca puede ser administrado simplemente como un medio para promover otros bienes que tengan que ver con el propio criminal (como propugnarían los defensores de la rehabilitación) o con los otros miembros de la sociedad (en lo cual se basarían los que abogan por la disuasión o la incapacitación), sino que debe ser impuesto en todos los casos por el simple hecho de que el delincuente cometió el delito y merece ser castigado por ello. La contundencia de las palabras de KANT habla por sí sola: «Aun cuando se disolviera la sociedad civil con el consentimiento de todos sus miembros, antes tendría que ser ejecutado hasta el último asesino que se encuentre en la cárcel, para que cada cual reciba lo que merecen sus actos» (KANT, 1797: 168-169).

La justificación de la pena basada en la retribución por el acto delictivo cometido puede entenderse desde una perspectiva racionalista. El argumento sería el siguiente. Si descartamos el determinismo (es decir, la doctrina según la cual todo lo que nos sucede en la vida se halla ya predeterminado, y que analizaremos más adelante), los seres humanos gozan de libre albedrío para tomar sus propias decisiones. Por eso, pueden decidir cometer o no un acto delictivo. Si deciden cometerlo, dado que esa decisión ha sido tomada de manera voluntaria, entonces se hacen responsables de las consecuencias de dicho acto.

Es por esa razón que deben recibir la pena que en justicia merecen, basada en la importancia del daño causado. Este es el principio de justo merecimiento (sobre el concepto de merecimiento, véase BETEGÓN, 1992: cap. IV). De este principio se sigue otro de no menor relevancia. Se trata del principio de proporcionalidad de la pena, que subraya la equivalencia que debe producirse entre el daño causado y la pena que se le asocia. Existen no pocos problemas a la hora de poder establecer una escala aceptable que asegure esta proporcionalidad entre el delito cometido y la pena a la que uno se hace 
acreedor, pero no voy a tratarlos aquí (véase VilajosanA, 2007: cap. V). Por último, la justificación retribucionista de la pena conlleva también sostener el principio de igualdad. Éste supone tratar de manera igual a los iguales. Quien cometa el mismo delito debe recibir la misma pena. Esto implica, entre otras cosas, que las penas correspondientes deben ser aplicadas con independencia del estatus social o personal tanto de los delincuentes como de las víctimas.

Tanto el principio de proporcionalidad como el de igualdad ponen de relieve que la justificación general de la pena (por qué castigar) tiene implicaciones respecto de la justificación de la medida en que está justificado castigar (cuánto castigar). Quien sostenga una justificación general de la pena de carácter retribucionista, está obligado por razones de consistencia a sostener también estos principios. En cambio, como veremos después, ni la proporcionalidad ni la igualdad tienen por qué darse en las demás formas de entender la finalidad de la pena.

\subsection{Disuadir}

Mientras que la retribución se orienta al pasado, la disuasión se orienta al futuro. Con la disuasión se pretende que no se produzcan de nuevo el tipo de hechos para los cuales se establece una pena. Nos dice BECCARIA: «el fin de las penas no es atormentar y afligir a un ser sensible, ni rectificar un delito ya cometido, sino impedir que el reo ocasione nuevos males a sus ciudadanos y retraer a los demás de cometer otros iguales» (BECCARIA, 1764: 73).

El fundamento que subyace a esta forma de justificar la pena es muy distinto del que está presente en los postulados retribucionistas. La pena, entendida como retribución, se impone porque el delincuente se lo merece, ya que ha incumplido un deber moral. Ello es así con independencia de las consecuencias que pueda tener este castigo en él o en la sociedad. En cambio, la imposición de la pena como disuasión sólo se puede justificar en tanto en cuanto origine consecuencias más beneficiosas que la alternativa de no imponerla. En este sentido, se trata de una justificación consecuencialista, y, más en concreto, utilitarista.

Es importante subrayar que el utilitarismo, y con él la idea de disuasión, también tiene en cuenta la racionalidad humana. Pero, a diferencia del retribucionismo que como vimos la contemplaba básicamente para adscribir responsabilidad a un individuo por sus actos, ahora la racionalidad se toma principalmente como aptitud para tomar decisiones inteligentes valorando los potenciales riesgos y beneficios de las acciones. En la versión de BENTHAM, por ejemplo, esto significaría que los delincuentes tomarían sus decisiones a través de un cálculo hedonista, sopesando las posibles ganancias y los potenciales riesgos de su acción. Entre esos riesgos deberían tener en cuenta la posibilidad de que sean condenados a una determinada pena (BENTHAM, 1789). En la actualidad, la teoría de la elección racional también enfatizaría esta idea, sofisticándola a través de cálculos de preferencias de los individuos.

Asumido lo anterior, si la pena pretende cumplir con su función disuasoria, su imposición debe suponer un coste más elevado para el posible delincuente que los beneficios que espera obtener del delito. Por ello, las medidas penales no se tomarían, al me- 
nos de manera principal, para cumplir con el principio de proporcionalidad (aunque hay que reconocer que BENTHAM admitió en su esquema un cierto nivel de proporcionalidad). De hecho, podría argumentarse que en determinadas condiciones, si la pena ha de tener efectos disuasorios, se requieren penas más duras de las que corresponderían según el principio de proporcionalidad. Del mismo modo, en determinadas situaciones, el planteamiento de penas excesivamente duras puede no conseguir este propósito, porque, por ejemplo, los jueces encargados de aplicarlas se muestren muy renuentes a hacerlo justamente porque perciben su desmesurada desproporción.

Este enfoque presenta diversos inconvenientes. Sólo destaco dos. Por un lado, el efecto disuasorio de la pena funciona seguramente de una manera en relación con delitos que exigen planificación y estrategia, por cuanto esta misma forma de operar implica un cierto cálculo (piénsese en el delito de estafa), mientras que es razonable pensar que opera de manera distinta, por ejemplo, en delitos pasionales (por ejemplo, algunos tipos de asesinatos o violaciones). Por otro lado, las diferencias personales pueden ser muy grandes. Baste tomar como punto de referencia la aversión al riesgo. Cada persona tiene un grado distinto de aversión al riesgo e incluso una percepción diferente del mismo (Massoglia; MacMillan, 2002). Pero acerca de estas cuestiones, no voy a decir aquí nada más (véase VILAJOSANA, 2007: cap. V).

\subsection{Incapacitar}

Otra de las posibles justificaciones de la pena es la llamada incapacitación. Ésta consiste en identificar y aislar al delincuente de la sociedad a la que pertenece para que no vuelva a cometer delitos. Seguramente es el objetivo más fácil de conseguir. Supone una justificación orientada al futuro, como la disuasión. Al igual que ésta, se centra en la prevención de futuros delitos. Su principal función es proteger la sociedad de aquellos sujetos que le han causado daños, privándoles de la oportunidad de que los vuelvan a ocasionar o al menos restringiendo sus posibilidades al máximo.

A lo largo de la historia podemos encontrar distintos modos de incapacitación, pero esto es entrar ya en la pregunta acerca de cómo castigar. De entre los tipos de incapacitación física, la forma extrema es la ejecución. Otros casos conocidos de incapacitación física son los de mutilación de miembros. También entrarían dentro de esta categoría las penas que suponen la castración en el caso de violadores. Un modo especial de incapacitar que, a diferencia de los anteriores, tiene efectos reversibles consiste en la utilización de sustancias químicas que pretenden reducir los impulsos sexuales. Sobre las posibilidades de utilizar este método que suele recibir el poco apropiado nombre de «castración química» diré algo más tarde. Actualmente, sin embargo, el método más utilizado de incapacitación es la encarcelación.

La justificación de la pena a través de la idea de incapacitación suele coincidir con postulados utilitaristas como en el caso de la disuasión. Los beneficios que la sociedad en su conjunto obtiene por el hecho de que los delincuentes estén encarcelados son que, mientras dura el encierro, éstos no pueden cometer actos delictivos. Pero en esta argumentación no entran en juego consideraciones de disuasión, de retribución por un acto inmoral o de rehabilitación. Tampoco, en principio, tiene por qué respetarse ninguna 
proporcionalidad entre el delito cometido y la pena aplicada. Si se es consecuente con este planteamiento, más bien lo que habría que decir es que cuánto más tiempo esté encarcelado un delincuente más tiempo estará segura la sociedad respecto de sus potenciales acciones dañinas. Si a esto sumamos el hecho de que estadísticamente se ha comprobado que las personas con la edad tienden a cometer menos delitos, entonces para quien sostenga esta posición hay una razón muy poderosa en favor de penas de larga duración.

Metodológicamente, existen menos problemas para determinar los efectos de la incapacitación que los que existen para averiguar si se produce disuasión. También es más fácil limitarse a ejercer el control de las personas que a reeducarlas, como requiere la rehabilitación que veremos más adelante. Siempre que sea correcta la presunción de que una persona que ha cometido un crimen, muy probablemente reincidirá, entonces se da con seguridad el efecto esperado con la incapacitación.

Una crítica que se puede hacer a esta forma de justificación del castigo, y que afecta a la pregunta acerca de cómo castigar, es también muy simple: la incapacitación se podría conseguir por otros medios que no resultaran tan lesivos para quien los sufre. Por limitarnos al caso de la imposición de penas privativas de libertad, aunque este tipo de penas se consideren justificadas, el entorno en el cual se cumplen las penas no tendría por qué ser desagradable. Se alcanzaría del mismo modo el objetivo de la incapacitación recluyendo a los delincuentes en un entorno paradisíaco.

Otra crítica, seguramente más decisiva, frente a esta posición sería relativa a la cuestión acerca de cuánto castigar. Ciñéndonos a las penas privativas de libertad, ocurre que quien quiera defender la pena por los efectos incapacitadores que ésta tenga sobre el delincuente, carecerá en principio de un criterio para determinar cuál es el tiempo que debe estar una persona en prisión, salvo que considere que cualquier delito debe ser castigado con prisión perpetua, lo cual no parece muy razonable.

\subsection{Rehabilitar}

Con la rehabilitación se pretende cambiar la intención, la motivación o incluso el carácter del delincuente respecto a su conducta frente al Derecho. Se asume que estos cambios ayudarán a modificar en sentido positivo la percepción de las leyes por parte del que alguna vez las incumplió. Aunque esta posición hunde sus raíces en la Ilustración, no es hasta finales del siglo XIX que alcanza un cierto nivel de aceptación. Se basa en postulados humanistas y propugna el abandono de las formas de castigo más duras. Tiene que ver, en su origen, con el rechazo de la tortura y de los castigos físicos. Con la rehabilitación, la centralidad que habían ocupado durante siglos los castigos físicos, ejemplarizantes, llevados a cabo en muchas ocasiones en público, pasará a ocuparla la persuasión de tipo psicológico.

Sin embargo, lo anterior no debería hacernos perder de vista el hecho de que algunos filósofos de la antigua Grecia propugnaron un cambio decisivo, que puede verse como un antecedente de las modernas doctrinas de la rehabilitación. Se trata de la propuesta de centrarse más en el delincuente que en el delito. Se partía de la base de que si alguien comete un delito lo hace porque tiene algún tipo de desajuste mental o mo- 
ral. Si esto es así, lo que debe hacerse es o bien curarle o bien enseñarle. Son emblemáticas en este sentido las palabras que PlatÓN pone en boca de SÓCRATES, según el cual nadie comete un acto inmoral a sabiendas. Dice SócrATES: «Hacia los males nadie se dirige por su voluntad, ni hacia lo que cree que son males, ni cabe en la naturaleza humana, según parece, disponerse a ir hacia lo que cree ser males, en lugar de ir hacia los bienes» (Platón, Protágoras: $358 \mathrm{~d}$ ).

Este mayor énfasis en el delincuente más que en el delito tiene consecuencias importantes desde el punto de vista de las preocupaciones teóricas de quienes abogan por la rehabilitación como objetivo de la pena. Antes hemos visto que quienes subrayan la importancia de otros objetivos, sobre todo en el caso de la disuasión, fundan sus diagnósticos teóricos en el análisis de la decisión racional. En cambio, cuando pasa a primer plano la preocupación por la rehabilitación del delincuente, la principal finalidad será averiguar y entender las causas subyacentes a la conducta criminal. De ahí que los estudios que intentan alcanzar esta finalidad se dediquen a investigar los distintos factores que influyen en dicha conducta, desde los biológicos a los psicológicos, pasando por los sociales. Esta posición llevará a negar o al menos a relativizar la premisa que servía de fundamento a las demás doctrinas: la presencia del libre albedrío. La conducta del delincuente es vista como el resultado de una suma de los factores citados que muchas veces quedan al margen del control del individuo. Ello conduce a una visión casi determinista de la acción humana, en el que las acciones escapan en buena medida al control de individuos supuestamente racionales, que como tales toman sus propias decisiones. Sobre esta cuestión volveremos más adelante. Sin embargo, en contraste con lo anterior, se insiste en la posibilidad de reeducar al delincuente, con lo cual se pone un gran énfasis en la labor que en esa dirección pueden llevar a cabo psicólogos, sociólogos o trabajadores sociales.

La rehabilitación, por tanto, está orientada al futuro y su justificación es de carácter utilitarista por cuanto también pretende evitar la comisión de nuevos crímenes. Estas son características que comparte con la disuasión, a diferencia de lo que ocurre con la retribución. Ahora bien, se distingue de ambos (disuasión y retribución) por el hecho de no asumir una completa racionalidad en los delincuentes.

Una consecuencia importante de fijarse más en el delincuente que en el delito, es que la pena no tiene por qué ser uniforme. Cuando el centro de atención es el acto delictivo, una vez determinado el tipo de delito que ha cometido una persona, se le asigna la pena correspondiente que será la misma que se le asignaría a otra persona que ha realizado el mismo tipo de delito. Esto, como vimos, cumple con el principio de igualdad propio de las ideas retribucionistas. Ahora bien, si el punto de mira se desplaza hacia el delincuente y sus posibilidades de rehabilitación, entonces la pena se debe asignar en función justamente de esas posibilidades, con independencia del delito que se haya cometido. Así, podría ocurrir perfectamente que dos personas que han realizado el mismo tipo de delito, con la presencia de las mismas circunstancias atenuantes o agravantes, recibieran una pena distinta, según el distinto período de tiempo que requieran sus respectivas rehabilitaciones.

Desde el punto de vista jurídico, esta consecuencia llevaría al establecimiento de sentencias indeterminadas, basándose en la idea de que individuos distintos requieren períodos distintos de rehabilitación, cuya duración no conocemos de antemano. Ade- 
más, como corolario de todo lo anterior, el peso de la decisión se desplaza de los jueces a los expertos en las distintas materias a las que antes he aludido (psicólogos, sociólogos, trabajadores sociales), los cuales son los encargados de dictaminar cuándo la persona que cometió el delito está rehabilitada y preparada para volver a vivir en sociedad.

El impacto de las ideas sobre la rehabilitación ha sido enorme. Difícilmente encontraremos un país occidental que no mantenga programas de rehabilitación generales o específicos. Es indudable que esta perspectiva tiene componentes humanitarios atractivos que seguramente hay que mantener. Ahora bien, la justificación de la pena basada en la rehabilitación también puede ser objeto de críticas.

Desde una perspectiva estrictamente jurídica, repugna a la idea de seguridad jurídica (porque no sabríamos de antemano qué pena le corresponderá a un determinado delito) y de justicia (precisamente por vulnerar los principios de justo merecimiento y de igualdad).

Además, no parecería muy lógico sostener, basándose en razones humanitarias, que penas como la cadena perpetua no están justificadas y en cambio defender, por las mismas razones, que las personas que no consiguen rehabilitarse deben permanecer toda su vida encerradas.

Otros problemas surgen de las disputas acerca de la eficacia de los programas de rehabilitación. No parece haber un acuerdo generalizado al respecto, ya que mientras algunos valoran estos resultados de manera muy positiva, otros se muestran muy críticos. No es posible entrar aquí en un análisis detallado de los distintos estudios empíricos que existen sobre la cuestión. En cambio, es oportuno preguntarse qué ocurre si se admite que al menos algunos tipos de delincuentes no son susceptibles de ser rehabilitados.

\section{VIOLADOR COMPULSIVO}

Para centrar el problema pensemos en lo que podríamos denominar «el caso del violador compulsivo». Los expertos parecen concordar, más allá de las estimaciones sobre el porcentaje de delincuentes que reinciden (que se suele situar entorno al 20 por 100), que existen casos especiales en los que las posibilidades de rehabilitación son prácticamente nulas. Son conocidos los supuestos, como los que se describen al comienzo de este trabajo, en los que un delincuente sexual que ha cumplido su condena o que se halla en una situación de libertad condicional, comete de nuevo agresiones sexuales. Supongamos que esa persona efectivamente no puede evitar cometer esos actos (debido a factores genéticos, por ejemplo), ¿cómo habría que actuar frente a estos casos? Más en general: ¿en qué medida afectaría al razonamiento de los defensores de la justificación de la pena a través de la rehabilitación la existencia de sujetos que no son susceptibles de ser rehabilitados?

Parece que la respuesta es clara. Si la pena se justifica por la rehabilitación del delincuente, en aquellos casos en los que se admite que no hay posibilidades de rehabilitación, no se puede justificar la imposición de una pena. Ahora bien, si de la perspectiva de la rehabilitación pasamos a la de la retribución, tampoco se resuelve el 
problema, ya que para determinar que el delincuente merece una determinada pena, tal como exige el retribucionismo, es menester que se muestre que la persona actuó voluntariamente, justamente lo que pone en duda la asunción de que el sujeto no puede hacer otra cosa.

Quedarían por examinar las posibilidades de la disuasión y la incapacitación. Respecto a la disuasión, parece que son de aplicación argumentos análogos a los que ya hemos utilizado anteriormente. Si no es posible rehabilitar al sujeto, mucho menos será posible disuadirlo de cometer este tipo de actos. La incapacitación, entonces, parece ser el último reducto para privar justificadamente de libertad a estos sujetos. Ahora bien, como ya dije en su momento, no se sigue que esta incapacitación deba llevarse a cabo en entornos punitivos, como son las prisiones, pero sí se sigue que no es de aplicación el principio de proporcionalidad, ni el de igualdad, con lo que no hay criterio para determinar penas distintas para distintos delitos. Así mismo, parece que es irrelevante que el comportamiento del individuo sea racional o no.

Llegados a este punto, cabe preguntarse si hemos dado una solución satisfactoria del problema. La respuesta es negativa. _nicamente hemos desbrozado algo el camino, pero nos queda todavía un buen trecho por recorrer. La razón es la siguiente. Hasta ahora he tratado la cuestión desde la perspectiva del primer interrogante que había planteado al inicio (por qué castigar) y, a lo sumo, desde el segundo (cuánto castigar), en la medida que está relacionado con el anterior. Pero, si se quiere avanzar, hay que formular los otros dos problemas pertinentes: a quién castigar y cómo hacerlo. Sólo cuando lo hagamos estaremos en condiciones de ofrecer una respuesta más desarrollada a la cuestión.

Para abordar estos problemas hay que dar un rodeo que pasa por examinar el desafío que el determinismo plantea para la justificación de la pena.

\section{EL DESAFÍO DEL DETERMINISMO}

\subsection{Preguntas inquietantes}

Podemos hacernos dos preguntas filosóficamente muy relevantes que giran entorno al problema del determinismo y la justificación de la pena:

a) Si se llegara a demostrar que todos los factores que influyen en la comisión de delitos escapan del control de los delincuentes, ¿estaría justificado moralmente seguir imponiéndoles penas?

b) En esas mismas circunstancias, ¿se podría seguir pensando que el establecimiento de penas puede tener un efecto disuasorio o que es posible la rehabilitación?

Como vemos, la primera de las preguntas afecta especialmente a la idea de la pena como retribución, mientras que la segunda tiene que ver directamente con el carácter disuasorio de la pena y las posibilidades de rehabilitación de los delincuentes. Intentemos responder a cada una de ellas.

La idea intuitiva que subyace al determinismo es que si admitimos que todo evento tiene una causa y que el mundo empezó en algún momento, se podría trazar al me- 
nos teóricamente una línea que uniera nuestras acciones con todas las causas precedentes. Dicho de otro modo, dado un conjunto de condiciones originarias del universo y dadas las leyes de la física que gobernarían todos los acontecimientos que suceden, existiría una única forma en la que las cosas pueden realmente suceder. Como ha puesto de relieve VON WRIGHT, la discusión que se produce respecto del determinismo guarda cierto paralelismo con las discusiones teológicas. De hecho, cuando fue desapareciendo la idea de un Dios omnipotente y omnisciente, su lugar fue ocupado por la visión determinista del mundo (VON WRIGHT, 1998: 29 y ss.).

Así, podría decirse que el determinismo es la doctrina que sostiene que el mundo es tal que cualquier estado de cosas que en él sucede está completamente determinado por $a$ ) las leyes de la física y $b$ ) por los estados de cosas anteriores (VAN INWAGEN, 1982). Por su lado, el libre albedrío exigiría, en principio (lo ha puesto en duda, por ejemplo, FRANKFURT, 1966), que una persona que hizo algo concreto hubiera podido hacer otra cosa. Ejercí mi libre albedrío en un caso determinado si cuando «decido» ir al parque, en realidad hubiera podido decidir ir al cine. Pero parece que si el determinismo es verdadero, entonces la de ir al parque es sólo una aparente decisión libre, puesto que estaba de hecho determinada, aunque yo no lo supiera, por causas sociales, psicológicas, etcétera.

En la discusión de filosofía general hay tres maneras posibles de afrontar el problema del determinismo. Una, que mantiene que el determinismo es verdadero, lo cual supone el rechazo del libre albedrío. Otra, que sostiene que el determinismo es falso y que puede darse el libre albedrío. Estas dos posiciones tienen en común el hecho de entender que el determinismo y el libre albedrío son incompatibles. En cambio, hay quien mantiene una tercera posición según la cual el determinismo y el libre albedrío pueden coexistir. Esta última posibilidad es la que muestra que el problema real del determinismo en relación con la libertad es hallar una respuesta satisfactoria a la probable verdad del determinismo (HONDERICH, 1993: 141). Esta respuesta es la que intentaré ofrecer más tarde.

\subsection{Razones que avalan la verdad del determinismo}

La investigación criminológica a finales del siglo XIX estuvo muy influida por la teoría darwiniana de la evolución. Los estudios de este tipo más conocidos se deben a C. LOMBROSO, un médico italiano que después de examinar a numerosos delincuentes llegó a la conclusión de que en su gran mayoría tenían unos rasgos biológicos muy distintos a los que no eran criminales, de lo cual dedujo que no habían alcanzado los niveles de evolución de sus congéneres (LOMBROSO-FERRARO, 1972). Esta doctrina cayó en desuso en años posteriores porque pareció absurda. Con ella también se arrinconaron supuestos estudios biológicos que pretendían demostrar que existía lo que ahora podríamos llamar un gen hereditario propio de delincuentes. Sin embargo, la línea de razonamiento que subyace a estos estudios no se abandonó nunca del todo. En la década de los años sesenta del siglo pasado resurgió al comprobarse que muchos criminales violentos poseían un cromosoma masculino extra, con lo cual se podría decir que tenían una predisposición genética a cometer actos violentos (HoOK, 1973). Otras investigaciones biológicas contemporáneas han matizado algo la cuestión, pero la línea 
de razonamiento sigue presente. Así, se dice que algunos individuos han nacido con factores genéticos hereditarios que los hacen más susceptibles a la influencia de entornos criminales. Algún autor ha sugerido que esos individuos tienen un sistema nervioso autónomo que es más lento a la hora de aprender a controlar su conducta agresiva. Por ello, es más probable que tengan un reiterado comportamiento antisocial (MEDNICK, 1980).

El resultado de este tipo de investigaciones supone un desafío a la justificación de la pena. Por un lado, pone en cuestión directamente la visión retribucionista, ya que ésta presupone el libre albedrío. Por otro lado, puede hacer replantear tanto la doctrina retribucionista como la disuasoria, por cuanto ambas presuponen un comportamiento racional del delincuente. En efecto, ¿'conseguiremos a través del establecimiento de penas disuadir a alguien de que cometa un delito para cuya realización está predispuesto genéticamente? Tampoco las posibilidades de rehabilitación escapan a este desafío, salvo que se pudiera intervenir en el componente genético de un individuo y se considerara que esta intervención está justificada moralmente.

Si del factor biológico o genético pasamos al psicológico, encontraremos de nuevo explicaciones de la conducta que tendencialmente presuponen el determinismo. Aunque FREUD no tuvo en mente la aplicación de sus doctrinas al ámbito de la justificación penal, la conexión de éstas con la visión determinista es inmediata. Pero las explicaciones freudianas del funcionamiento del cerebro son del tipo de caja negra. Podían explicar lo que entraba y lo que salía del cerebro, pero no los procesos que se desarrollaban en su interior. Este déficit explicativo es el que pretenden subsanar los estudios contemporáneos de neuropsicología. Entre ellos, destaca para nuestros propósitos el dedicado al análisis de las funciones del córtex prefrontal.

De hecho, la literatura sobre esta cuestión es ingente y se remonta a hace más de 150 años. En 1848, Phinneas Gage sufrió un accidente laboral que le destruyó limpiamente esa parte del cerebro. De resultas del accidente, Gage, que había sido hasta entonces una persona digna de confianza y trabajador, pasó por lo visto a tener comportamientos antisociales, de tal manera que no era reconocible por familiares y amigos (sin embargo, el carácter radical de este cambio tantas veces contado ha sido puesto en duda últimamente en MACMILLAN, 2000). Estudios posteriores y diversos experimentos han mostrado, aunque de una manera más sofisticada, que esta parte del cerebro cuando resulta dañada o está poco desarrollada incide en la capacidad de tener respuestas empáticas, por lo que esas personas pueden parecer carentes de sentimientos. Pero nótese una cosa: estos individuos no han elegido ser así; lo son por accidente o por herencia genética. ¿Les seguiremos atribuyendo responsabilidad por sus actos? Y lo que es más importante, a medida que se avance en los estudios de neurociencia, ¿no es de esperar que se hallen otras tantas «causas» de nuestro comportamiento y con ello se acabe desvaneciendo la idea de que somos tan libres en nuestra toma de decisiones como para merecer un castigo por las equivocadas?

En los países de nuestro entorno ya se tienen en cuenta algunas circunstancias de un funcionamiento «anormal» del cerebro por enfermedad, como la epilepsia, o por ingesta de sustancias estupefacientes. Si una persona comete un acto delictivo en estas circunstancias puede atenuarse o incluso excluirse su responsabilidad. En cambio, se marca una diferencia entre ese funcionamiento anormal y el normal, admitiendo que 
en este último caso la persona eligió voluntariamente realizar el acto por el cual merece un castigo, amparándose muchas veces en la idea de que era capaz de distinguir el bien del mal. Ahora bien, ya hay algunos científicos que ven ahí una falsa dicotomía (SAPOLSKY, 2006: 239), entre un campo en el que dominarían las causas biológicas y otro en el que todavía existiría libre albedrío. Según estos científicos, lo que mostraría la literatura sobre el córtex prefrontal es que una persona, por razones de constitución orgánica y a pesar de conocer la diferencia entre lo correcto y lo incorrecto, puede ser incapaz de bacer lo correcto.

Un argumento en contra de lo anterior podría ser que hasta donde ahora se sabe, el daño sufrido en esta parte del cerebro predispone pero no determina totalmente a la persona a cometer actos delictivos. La prueba es que sujetos que tienen el córtex prefrontal dañado no han cometido ningún delito. ¿Deja resquicio esta duda para argumentar a favor del libre albedrío? Según algunos autores, este tipo de preguntas no están bien formuladas, por cuanto presuponen que hay una distinción clara entre una persona con córtex prefrontal dañado (en el que supuestamente no habría libre albedrío) y otra en que esta parte del cerebro no ha sufrido daños (a la que le podríamos adjudicar una voluntad libre). Parece, más bien, que la ciencia en estos casos se mueve por continuos y no puede trazar una frontera clara entre un caso y el otro, mientras que en el caso del Derecho exigimos dicotomías: o existe justificación o excusa para la conducta tipificada como delito o no es así, sin que quepa hablar de una persona más o menos culpable (SAPOLSKY, 2006: 240).

Además de los factores biológicos y psicológicos (o neuropsicológicos), se argumenta en ocasiones que existen también factores socioeconómicos que ayudan a explicar las causas por las que los sujetos actúan de manera antisocial y a menudo delictiva. En esta línea de pensamiento hallaríamos diversos estudios llevados a cabo en el departamento de sociología de la Universidad de Chicago, en la primera mitad del siglo XX, pasando por las llamadas teorías de las subculturas, que se desarrollaron algo más tarde (véase SHICHOR, 2006: 43-50). El elemento común de este tipo de estudios es justamente el intento de explicar la conducta criminal desde postulados casi deterministas. Para estas doctrinas, las condiciones sociales y la atmósfera cultural de ciertos barrios marginales de núcleos urbanos son tales que para los jóvenes que en ellos nacen resulta si no imposible sí al menos muy difícil no caer en las redes de la delincuencia. Por eso, a pesar de que no se suele defender un extremo determinismo social del mismo modo que se defiende un determinismo psicobiológico, al menos de manera tendencial estas posiciones cuestionan también el papel del libre albedrío de los seres humanos en sociedad.

\section{3. ¿Cómo hacer frente al desafío?}

El determinismo en los factores genéticos, psicológicos y, en menor medida, socioeconómicos, plantea como hemos visto serios problemas para la justificación de la pena. ¿Cuál puede ser la forma de escapar de éstos? Una primera salida puede ser la de renunciar a los postulados retribucionistas y quedarse con los utilitaristas. Es lo que hacen algunos científicos (por ejemplo, GREEN y COHEN, 2004) y algunos juristas que postulan la necesidad de desvincular completamente la culpabilidad de la capacidad de 
actuar de otro modo (por ejemplo, GIMBERNAT, 1990). Los defensores de esta posición nos vienen a decir algo así como que si la libertad es incompatible con el determinismo, tanto peor para la libertad (WEATHERFORD, 1991: 93). Ahora bien, pensemos que no toda idea utilitarista puede ser defendida por estos medios. Seguramente, la única que podría resistir el envite determinista sería la idea de incapacitación, pero no así la disuasión ni la rehabilitación.

En efecto, tal como dije en su momento, la disuasión requiere creer en la racionalidad estratégica de las personas. La racionalidad estratégica exige, por su parte, que el sujeto pueda tomar su decisión voluntariamente. Pero si aceptamos como premisas de nuestro razonamiento la verdad del determinismo y la falsedad del libre albedrío, entonces no hay acciones voluntarias y decaen los postulados en los que se basa la racionalidad estratégica, de la que depende el éxito de las políticas de disuasión: las personas hacen lo que hacen porque no pueden hacer otra cosa. Así como el problema que el determinismo plantea para la justificación retribucionista de la pena es vista por todos, el que origina a quienes parten de postulados utilitaristas a través de la racionalidad no parece ser comúnmente reconocida (por ejemplo, en HIERRO, 1989: 595 y ss., parece aceptarse que la justificación de la pena por medio de la prevención no se vería afectada por la verdad del determinismo).

La rehabilitación también sería difícilmente defendible a través de esta argumentación, por cuanto exige igualmente la posibilidad de que nuestras acciones tengan impacto en las de los demás. Sin esta premisa, no es posible la reeducación. Además, también las conductas de los reeducadores (psicólogos, trabajadores sociales) estarían determinadas por causas ajenas a su decisión y por las leyes de la física. No se podría «elegir» tener una política rehabilitadora o no. Estos problemas no parece que tengan solución para quien trate al determinismo y al libre albedrío de manera incompatible. En este caso, la verdad de uno implica la falsedad del otro, con las consecuencias que acabo de mencionar.

Frente a estos inconvenientes, hay otra forma de encarar la cuestión: reconocer que, de alguna manera, la verdad del determinismo puede coexistir con la presencia del libre albedrío. Esto se puede hacer, por ejemplo, mostrando que el determinismo y el libre albedrío se mueven en planos distintos. Se trata de reconocer que, con independencia de que el determinismo pueda ser verdadero (algo que, por lo demás tampoco podemos establecer con total rotundidad), no podemos imaginarnos a nosotros mismos en un mundo que no reconozca la existencia del libre albedrío y, con él, de las ideas retribucionistas. La pregunta, entonces, pasa a ser si es humanamente posible negar nuestros impulsos retribucionistas. En este sentido, STRAWSON desarrolló un argumento que ha sido posteriormente empleado en otros ámbitos y por otros autores (STRAWSON, 1962; recientemente, por ejemplo, PETTIT, 2002) y que merece una cierta atención.

STRAWSON empieza destacando un lugar común central: la gran importancia que damos los seres humanos a las actitudes e intenciones que adoptan hacia nosotros otros seres humanos. Nuestros sentimientos y reacciones personales dependen en gran medida de nuestras creencias acerca de estas actitudes e intenciones o, en todo caso, las involucran. Dice este autor que si alguien nos pisa la mano accidentalmente mientras está tratando de ayudarnos, el dolor podrá no ser menos agudo que si lo hace con despectiva desconsideración hacia nuestra existencia o con el malévolo deseo de herirnos. 
Pero, en general, en el segundo caso sentiremos un tipo y grado de resentimiento que no sentiremos en el primero. Si las acciones de alguien nos sirven para lograr una ventaja que deseamos, entonces nos benefician en cualquier caso; pero si su intención es que nos beneficien a causa de una buena voluntad general hacia nosotros, sentiremos con razón una gratitud que no sentiríamos en absoluto si el beneficio fuese consecuencia incidental, no querida o incluso lamentada por nuestro benefactor. Estas reacciones se pueden identificar claramente como actitudes que tenemos al entrar en relación con otras personas, como son por ejemplo las actitudes de resentimiento o gratitud. Estas actitudes pueden llamarse actitudes participativas.

Ahora pensemos en qué tipo de reacciones tenemos frente a un agente psicológicamente anormal o moralmente inmaduro, como un neurótico o simplemente un niño. Cuando vemos a alguien desde esta perspectiva, todas nuestras actitudes reactivas tienden a modificarse profundamente. Entonces, STRAWSON compara la actitud de involucrarse en una relación humana, de una parte, con lo que denomina la actitud objetiva hacia un ser humano diferente, de otra. La adopción de la actitud objetiva hacia otro ser humano consiste en verle, quizás, como un objeto de estrategia social, como objeto de tratamiento. En definitiva, lo que pretende destacar este autor por encima de todo es la tensión que existe en nosotros entre la actitud participativa y la actitud objetiva.

Una vez vistos estos dos tipos de actitudes humanas, la pregunta pasa a ser: ¿Podría, o debería, la aceptación de la tesis determinista conducirnos siempre a ver a todo el mundo exclusivamente de la manera objetiva? Pues ésta es la única condición bajo la cual la aceptación del determinismo podría conducir al debilitamiento o al repudio de las actitudes reactivas de participación. Al respecto, STRAWSON cree que no es contradictorio suponer que tal cosa pueda pasar, pero que, conforme somos, nos resulta prácticamente inconcebible.

Una objetividad sostenida en la actitud interpersonal, y el aislamiento humano que llevaría consigo, no parece ser algo de lo que seamos capaces los seres humanos, incluso aunque hubiese alguna verdad general que le sirviera de fundamento teórico. Pero, además, cuando de hecho adoptamos semejante actitud en un caso particular, el que hagamos tal cosa no es consecuencia de una convicción teórica que podríamos denominar «determinismo del caso concreto», sino una consecuencia de que, por razones diferentes en diferentes casos, abandonamos nuestras actitudes interpersonales ordinarias. Piénsese incluso, tal como nos recuerda NiNO, que el carecer de distinción entre quienes son imputables y quienes no, afectaría a otras esferas del Derecho, más allá del Derecho penal. Así, si nos pudiéramos tomar en serio la verdad del determinismo y fuéramos capaces de incorporarlo a nuestra forma de ver la vida, deberíamos arrinconar la posibilidad de celebrar contratos válidos: los contratos serían siempre nulos por fuerza mayor, puesto que el consentimiento siempre estaría viciado (NINO, 1980: 379 y ss.).

Finalmente, a la pregunta ulterior de si no sería racional, bajo la convicción teórica de la verdad del determinismo, cambiar nuestro mundo de tal manera que se suspendan en él todas estas actitudes, STRAWSON responde que es inútil preguntar si no sería racional para nosotros hacer lo que no está en nuestra naturaleza poder hacer. Y frente a la idea de que los avances en el conocimiento de los seres humanos (como por ejemplo los producidos en el campo de la neuropsicología, a los que ya hice referen- 
cia) llevarían a la desaparición de esas actitudes, este autor responde que podemos razonablemente considerar improbable que una progresivamente mayor comprensión de ciertos aspectos de nosotros mismos conduzca a la desaparición total de esos aspectos.

Por eso, no parece que se vaya muy lejos trazando la distinción entre la posibilidad de adoptar una perspectiva interna (que permite dar cuenta de nuestra forma de atribuir responsabilidad) y otra externa (que permitiría dar cuenta de nuestra visión determinista del mundo), añadir que la externa le está vedada a los seres humanos y en cambio propugnar que se requiere una combinación de ambas (como sugiere, por ejemplo, MOLINA FERNÁNDEZ, 2000: 125 y ss.). Si no somos capaces de adoptar como seres humanos la perspectiva externa, entonces no tiene sentido que digamos que debemos combinarla con la interna. Creo que esto justamente es lo que pone de relieve STRAWSON.

La posición de STRAWSON, por cierto, ha recibido un nuevo impulso a través de descubrimientos recientes en el ámbito de las ciencias del comportamiento, que sugieren que existe un sentido intuitivo de equidad incorporado profundamente en nuestros ancestros primates (BROSNAN y DE WAAL, 2003), así como que una tendencia adaptativa hacia la pena en sentido retribucionista puede haber tenido un papel decisivo en la evolución biológica y cultural de la sociabilidad humana (BOwLES y GINTIS, 2004). Parece, pues, que las ideas retribucionistas no sólo pertenecen a nuestras ideas intuitivas del modo en que pertenecen otras y que llegado el caso las podemos abandonar si nos lo proponemos, sino que pertenecen al ser humano de una manera tan profunda que, de no tenerlas, las personas dejarían de ser tal como las conocemos. Además, las ideas retribucionistas han sido evolutivamente útiles en el desarrollo de las sociedades humanas.

La lección que podemos extraer del anterior análisis acerca del determinismo es que, si aceptamos las ideas que he expuesto, entonces la justificación retribucionista de la pena es inevitable, mientras sigamos siendo como somos. Mientras sigamos siendo como somos, será imprescindible reconocer la presencia en nosotros de dos tipos de actitudes, de participación y objetivas. Ahora bien, este carácter inevitable de las ideas retributivas no tiene por qué darse respecto a todos los interrogantes que formulé al comienzo del trabajo.

Lo que es inevitable, si tenemos estas actitudes, es que este hecho tenga su reflejo a la hora de responder la pregunta acerca de quiénes deben ser los destinatarios de las penas. Así, que tengamos actitudes participativas hace que reconozcamos responsabilidad a los demás por sus actos, que es tanto como decir que la clase de los sujetos responsables no puede ser vacía. Que tengamos actitudes objetivas en algunos casos, lleva, a su vez, a establecer una clase de individuos, cuyas acciones quedan fuera de las reacciones de reproche o de gratitud, que es tanto como decir que nos permite justificar la existencia de una clase de personas inimputables. Y lo que hemos aprendido al respecto, tal vez sea que dentro de esa clase deberían estar no sólo quienes no son capaces de distinguir lo correcto de lo incorrecto, sino aquellos que pudiendo hacer esta distinción, en cambio no son capaces de hacer lo correcto.

Sin embargo, las ideas retribucionistas no necesariamente deben aparecer cuando se plantean las demás cuestiones, como pone de relieve el llamado por HART «principio de retribución en la distribución», que paso a analizar a continuación. 


\section{EL PRINCIPIO DE RETRIBUCIÓN EN LA DISTRIBUCIÓN}

\subsection{Una justificación utilitarista}

Este principio, en realidad, puede ser reconstruido como la conjunción de dos principios:

1. Nadie debe ser castigado por un delito que no haya cometido, intentado o planeado. Este principio puede ser llamado el principio de la persona correcta.

2. Nadie debe ser castigado por un delito que haya cometido sin mens rea, es decir, sin intención o con la presencia de excusas. Este principio puede llamarse el principio de culpabilidad.

HART entiende que se puede hacer referencia a la retribución en dos niveles distintos. Por un lado, el que hemos visto como una respuesta a la pregunta de por qué castigar, en el que la retribución designaría el fin general justificativo del sistema penal. Por otro lado, el empleado a la hora de contestar la pregunta «¿a quién se puede infligir la pena?». Esta última es la cuestión a la que HART llama de distribución. Cuando a esta pregunta contestamos diciendo que únicamente podemos infligir el castigo a un transgresor de una norma por su transgresión voluntaria, estamos dando la respuesta que daría un defensor de la retribución en la distribución.

Según este autor, existe una gran confusión entre los utilitaristas y sus adversarios precisamente por no haber distinguido convenientemente entre los dos niveles mencionados: la retribución como fin general y la retribución en la distribución. Por supuesto, existen relaciones entre ambos niveles. Pero, así como el sostener la retribución como fin general justificativo de la pena implica mantener la redistribución en la distribución, la inversa no se da. Por ello, es perfectamente compatible sostener una justificación general de la pena de corte utilitarista y en cambio defender la retribución en la distribución. Así, se puede decir, tal como hace HART, que el fin general que justifica la práctica del castigo es que esta práctica genera consecuencias beneficiosas para la sociedad y añadir a renglón seguido que la consecución de este fin general debe estar condicionado o limitado por el respeto a los principios anteriormente citados (HART, 1968: 11-12).

Para HART, por tanto, la justificación general de la pena es utilitarista (para una versión desarrollada a partir de las ideas hartianas, véase TEN, 1987). Pero, como es sabido, el utilitarismo presenta algunos problemas para su justificación. Entre ellos ocupa un lugar destacado el hecho de que en determinadas circunstancias a través de sus postulados se puede llegar a justificar moralmente que se penalice a un inocente. A esta insatisfacción pretende dar respuesta el principio de la persona correcta. Así, se da cabida a una intuición moral que todos tenemos, aunque pueda parecer que con ello se entra de lleno en una justificación, la retributiva, que es contradictoria con la utilitarista. Pero esto, para HART, no es así.

HART, en efecto, entiende que el principio de la persona correcta que parece propio del retribucionismo, puede ser justificado a través de razones utilitaristas. Por esa razón, este autor considera que el principio de la retribución en la distribución tiene un valor casi independiente de una justificación retributiva. Un sistema penal que facultara a las autoridades para castigar a los inocentes, sería visto con tal aprensión y genera- 
ría tal inseguridad que cualquier ganancia que pudiera producir el ejercicio de esas facultades se vería contrarrestada por la miseria causada por su existencia. Y este argumento es de corte utilitarista y bastante razonable siempre que se utilice en relación con una sociedad abierta como la que está pensando HART. Sin embargo, el argumento resultaría más débil si se quisiera extender su radio de acción a las sociedades que actuaran con mayor secretismo y sin la presencia de medios de información libres, ya que lo que cuenta para la disuasión no es lo que realmente se hace, sino lo que parece que se hace. Pese a este inconveniente, el planteamiento encaja bien con los modernos sistemas penales, en los que podemos hallar muchas disposiciones que están basadas en tales principios.

De todos modos, parece que el principio de culpabilidad puede generar mayores problemas dadas sus múltiples variantes de aplicación. Los distintos sistemas jurídicos reconocen razones de varios tipos por las que un individuo, aun habiendo realizado el acto delictivo (por acción u omisión), puede ser considerado no sujeto a responsabilidad. Así, hallamos causas de justificación, como es el caso de la legítima defensa o excusas como el hecho de haber realizado el acto bajo coacción. El sujeto puede haber realizado el acto también sometido a algún tipo de situaciones que hacen que «no sea él mismo», como por ejemplo en estados de epilepsia, o por influencia de un importante desorden mental. Puede suceder, por último, que el acto en cuestión sea realizado por accidente o por alguien que es menor de edad.

Todas estas situaciones pueden presentar problemas. Pero, aunque los resolvamos, un utilitarista puede sostener que a pesar de que se den estas circunstancias, algo se debe hacer para evitar tales actos en la medida de lo posible, por cuanto ocasionan daños. De hecho, muchas veces el incremento en alguno de estos supuestos origina la aparición de nuevos delitos. Un caso paradigmático lo tenemos con el incremento de los accidentes automovilísticos. Ello da lugar a un deseo legítimo por reducir la tasa de siniestralidad. Y para ello, en muchas ocasiones se califica de delito el hecho de poner en riesgo la vida de las personas a través de la tipificación de delitos contra la seguridad en el tráfico. Por tanto, una justificación general de la pena de corte utilitarista parece exigir algo más que la retribución en la distribución.

\subsection{Una justificación basada en el autointerés}

Por todo lo dicho hasta ahora pudiera parecer que lo único que se puede hacer en el ámbito de la justificación de la pena es optar por una visión retribucionista pura, o una visión utilitarista pura, o bien por una combinación de ambas. Sin embargo, puede resultar de interés adoptar una visión que nos permita una justificación de ideas tan intuitivas y tan extendidas en nuestros ordenamientos como las planteadas por el principio de retribución en la distribución, pero a partir de postulados que no son ni retributivos ni utilitaristas. Tal vez con ello se puedan encarar de otra forma algunos de los callejones sin salida que se suelen encontrar en este tipo de debates entre retribucionistas y utilitaristas.

La idea la podríamos tomar de RAWLS y su forma de hallar los principios de justicia que deberían regir las instituciones en una sociedad justa y aplicarla a los supuestos 
de justificación de la pena (WALKER, 1991: 92-93). Como es sabido, la propuesta de RAWLS consiste en la realización de un experimento mental. Deberíamos colocarnos en la posición de una persona que decidirá por el propio interés, es decir, sin tener en cuenta consideraciones de carácter altruista y colocada tras un velo de ignorancia. Este velo no le dejará saber si una vez retirado se hallará en una posición privilegiada, si será inteligente o no, si tendrá mayores o menores capacidades o si será incompetente. Tampoco le permite saber en qué estadio económico se encontrará la sociedad en que le tocará vivir. RAWLS argumenta que si esa persona es racional y autointeresada optará por una sociedad organizada de una determinada manera: en un sentido vago, pero que es suficiente para lo que aquí importa, se tratará de una sociedad en la que existirán igualdad de oportunidades de alcanzar un cierto bienestar por parte de todos sus ciudadanos (RAWLS, 1971).

Ahora imaginemos que esta persona que tiene que decidir bajo estos condicionantes desconoce si se encarnará, una vez quitado el velo, en una persona cumplidora de la ley o bien en un delincuente. Supongamos, además, que se le ofrecen dos opciones para poder elegir. Una primera opción consiste en vivir en la sociedad A, en la que se respetarán los principios de la persona correcta y el de culpabilidad. Escoger la segunda opción supone vivir en una sociedad B, en la que no se respetan estos principios. En la sociedad A esta persona podría ser castigada únicamente por los delitos que haya cometido de manera culpable. En la sociedad B, en cambio, podría ser castigada por delitos de los que no es responsable (a tenor de los principios citados). Puesto que por hipótesis la persona en cuestión puede encarnarse en dos roles distintos, cumplidor de normas o delincuente, ¿qué ocurrirá en cada uno de estos casos? Si le toca ser delincuente, en las sociedades A y B se le podrá castigar por los delitos que ha cometido, pero en la sociedad B se le podrá castigar, además, por delitos de los que no sea culpable. Desde esta posición, parece que la elección racional debe ser vivir en la sociedad A. Por el contrario, si se encarna en una persona cumplidora de las leyes, se encontrará que en la sociedad A nunca podrá ser castigado, pero sí que lo podrá ser en la sociedad B. Parece claro que en este caso su elección racional será también vivir en la sociedad A. Por tanto, en cualquier circunstancia, un sujeto racional y auto interesado preferirá vivir en la sociedad A y no en la sociedad B.

Fijémonos bien: esta justificación no es utilitarista. La sociedad que elegiríamos en estas circunstancias no tiene por qué ser la que tenga, por ejemplo, un índice de criminalidad menor. Si la sociedad B presenta un menor índice de criminalidad que la sociedad A, podría estar más justificada que ésta desde un punto de vista utilitarista. En cambio, este dato es irrelevante en el argumento que acabo de dar. Por otro lado, el razonamiento que hemos llevado a cabo no se basa tampoco en razones de merecimiento. Se trata simplemente de una cuestión de elección racional, de individuos que velan por su propio interés.

\section{EL DILEMA DE LA CASTRACIÓN QUÍMICA}

Dejamos aparcada en su momento la cuestión acerca de la justificación de la pena en relación con el caso del violador compulsivo, diciendo que en función de la pregunta de por qué castigar, parecía que la única opción plausible era la relativa a la incapa- 
citación. Lo dicho en los anteriores apartados nos permite avanzar una respuesta más elaborada, aunque seguramente más decepcionante.

Ello supone afrontar la pregunta acerca de cómo implementar la pena. Para simplificar, imaginemos que la incapacitación se pueda lograr o bien a través de la privación de libertad o bien a través de la castración química. Aunque consideráramos acertada la primera medida, como ya dije, no hay razón que justifique su implementación en un entorno desagradable y carecemos de criterios para establecer un determinado plazo de cumplimiento de la pena.

Pero por ahora concentremos nuestra atención en la llamada «castración química». Esta alternativa consiste en la administración de medicamentos para suprimir la líbido del individuo. Fue diseñada para el tratamiento del cáncer de próstata avanzado. Lo que hace la castración química es utilizar unas sustancias que bloquean la producción de testosterona en los testículos. El fármaco actúa en el cerebro del individuo, en la glándula hipófisis, inhibiendo la producción de la hormona. La testosterona es una hormona esencial para un correcto funcionamiento de la sexualidad masculina. Por eso, cuando la testosterona desaparece del organismo se produce una disminución del impulso sexual, o líbido, en el hombre. Ello debería de llevar al violador compulsivo a no cometer más agresiones sexuales.

En muchos países, también en el nuestro, desde hace tiempo existen programas a los que los delincuentes sexuales pueden someterse voluntariamente. La primera pregunta que debemos hacernos es si son efectivos estos programas. En primer lugar, los expertos creen que la lista de efectos secundarios, a veces graves, podría disuadir a los delincuentes de continuar el tratamiento. En segundo lugar, diversos especialistas creen que estos medicamentos no son efectivos por sí solos y subrayan, por tanto, que tales tratamientos no pueden ir aislados. Por esta razón, se suelen acompañar con otras terapias, como asesoramiento psicológico y tratamientos antidepresivos. Sin embargo, hasta ahora no se ha logrado obtener pruebas científicas que confirmen que estos tratamientos sean realmente exitosos. Más bien se ha puesto de relieve en diversas ocasiones que el delincuente, aun sujeto a ese tipo de tratamientos, ha reincidido, por ejemplo cometiendo agresiones sexuales con objetos. Pero, si de hecho estos tratamientos son poco eficaces, entonces decae la razón básica para adoptarlos desde el punto de vista de la incapacitación como modelo justificativo de la pena.

Ahora bien, desde el punto de vista filosófico se puede ir más allá. Imaginemos que estos tratamientos son exitosos, en el sentido de que en ningún caso de los que se aplican se produce un nuevo delito, ¿deberemos entonces considerarlos justificados moralmente? Llegamos así a un punto central de la justificación de la pena, en el que se entrecruzan en realidad dos problemas, uno relativo a la justificación de los destinatarios (a quién se castiga) y otro que tiene que ver con la justificación del cómo se castiga.

Respecto a la primera cuestión, se puede decir que, por un lado, está el hecho de considerar responsables de sus actos a los sujetos que cometen de manera reiterada este tipo de delitos. Si lo son, a tenor del principio de retribución en la distribución, entonces deben cumplir la pena correspondiente. Pero, si por el contrario, se les considera inimputables, según ese mismo principio, entonces no se les puede considerar respon- 
sables de sus actos. Parece que si se acepta la extensión de la clase de los inimputables, cumpliendo con el principio de culpabilidad, a quienes aun sabiendo distinguir lo correcto de lo incorrecto, no son capaces de hacer lo correcto, estos individuos no podrían ser considerados responsables.

El problema en que nos hallamos ahora, y que subsistirá o incluso se agravará en algunos de los proyectos de reforma que están en marcha, es que se intentan combinar ambos puntos de vista, que en este punto son incompatibles. Puesto en sus crudos términos: o a estos sujetos se les trata como responsables de sus actos y entonces se les condena como a todo delincuente (con sus deberes, pero también con sus derechos), o se les considera inimputables, puesto que se trata de enfermos mentales, en cuyo caso no cabe la aplicación de ninguna pena en sentido estricto y hay que intentar la vía del tratamiento médico. El mantener ambas posiciones, simultáneamente (aplicando la pena y el tratamiento al mismo tiempo) o sucesivamente (aplicando primero la pena y después, una vez cumplida ésta, el tratamiento), no parece tener justificación.

En relación con la segunda cuestión y si se acepta todo lo anterior, entonces surge un dilema respecto a qué medida hay que emplear en estos casos.

Si se opta por la imposición de una pena privativa de libertad, la única justificación posible de la misma, como sabemos, sería la relativa al objetivo de la incapacitación. Pero tomar esa medida, tiene el coste de sacrificar el principio de retribución en la distribución, ya que los sujetos a los que se va aplicar son inimputables y además parece que sólo cabría la condena de por vida, al carecerse de un criterio para delimitar temporalmente la pena.

Si se opta por el empleo de la castración química, caben dos opciones: que esa medida se considere la imposición de una pena o que se tome como un tratamiento médico. Si se la considera una pena, no se puede aplicar a los violadores compulsivos, ya que éstos son inimputables (salvo que se quiera de nuevo sacrificar el principio de retribución en la distribución). Si por el contrario recibe la consideración de tratamiento médico, entonces estos sujetos, por una simple aplicación del principio de dignidad, tienen que prestar su consentimiento informado (como cualquier paciente), con lo cual la sociedad se expone a que alguno no quiera recibir tratamiento o que queriendo recibirlo no resulte eficaz.

Debe quedar claro, para finalizar, que lo que aquí he expuesto es relativo a la justificación de la pena. He dejado al margen la posibilidad de dar buenas razones a favor de llevar a cabo medidas de seguridad en estos casos. Por lo que ahora interesa, se suele entender que respecto a la pena se requiere un juicio de reproche, basado en el principio de culpabilidad, que, en cambio, no se exige para justificar las medidas de seguridad. En este sentido, del mismo modo que se podría intervenir para «curar» a personas que pueden transmitir una enfermedad por hallarse infectados con un virus capaz de provocar una epidemia en una determinada población, análogamente cabría intervenir, aun contra la voluntad de los violadores compulsivos, a través de medidas como la castración química para evitar los males seguros que se originarían de tal omisión. Esto se podría justificar siempre que se probara que este tratamiento es efectivo (lo cual, como hemos visto, no está nada claro) y es el menos costoso tanto para la sociedad como para el individuo al que se le aplicaría. 


\section{BIBLIOGRAFÍA CITADA}

BeCCARIA, C., 1764: De los delitos y de las penas. Traducción castellana de J. JorDÁ, 1983: Barcelona.

Bentham, J., 1789: An Introduction to the Principles of Morals and Legislation, J. H. BuRns y H. L. A. HART (eds.), 1970: London: The Athlone Press.

Betegón, J., 1992: La justificación del castigo, Madrid: Centro de Estudios Constitucionales.

Bowles, S., y GinTIS, H., 2004: «The Evolution of Strong Reciprocity: Cooperation in Heterogeneous Populations», Theoretical Population Biology, 65: 17-28.

Brosnan, S. F., y DE WaAL, F. B. M., 2003: «Monkeys Reject Unequal Pay», Nature, 425: 297-299.

FrAnkfurT, H., 1966: «Alternate Possibilities and Moral Responsibility», Journal of Philosophy, 66: 829-839.

GimBERnAT, E., 1990: «¿Tiene un futuro la dogmática jurídico-penal?», en Estudios de Derecho

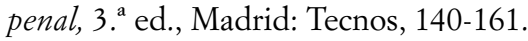

GreEn, J., y Cohen, J., 2004: «For the Law, Neuroscience Changes Nothing and Everything», en S. ZeKi y O. GoOdenough (eds.), Law and the Brain, Oxford: Oxford University Press, 207-226.

Hart, H. L. A., 1968: Punishment and Responsibility. Essays in the Philosophy of Law, Oxford: Oxford Clarendon Press.

Hierro, L., 1989: «Libertad y responsabilidad penal», Anuario de Derecho Penal y Ciencias Penales, 565-602.

Honderich, 1993: How Free are You? The Determinism Problem, Oxford: Oxford University Press. Traducción castellana de A. P. MOYA, 1995: ¿Hasta quépunto somos libres? El problema del determinismo, Barcelona: Tusquets.

Hook, E. B., 1973: «Behavior Implications of the Human XYY Genotype», Science, 179: 139-150.

KANT, I., 1797: La metafísica de las costumbres. Traducción castellana de A. CoRTinA y J. ConiLl, 1989: Madrid: Tecnos.

Lombroso-Ferraro G., 1972: Criminal Man According to the Classification of Cesare Lombroso, Montclair: Paterson Smith. La publicación original data de 1911.

MacMillan, M., 2000: An Odd Kind of Fame: Stories of Phinneas Gage, Cambridge: MIT Press.

Massoglia, M., y MacMillan, R., 2002: «Deterrence, Rational Choice, and Criminal Offending: A Consideration of Legal Subjectivity», en A. R. PIQUero y TibBETTS (eds.), Rational Choice and Criminal Behaviour, New York: Routledge, 323-340.

Mednick, S. A., 1980: «Primary Prevention of Juvenile Delinquency», en D. SHICHOR y D. H. Kelly (eds.), Critical Issues in Juvenile Delinquency, Lexington: D. C. Heath, 263-277.

MOLINA FERNÁNDEZ, F.: «Presupuestos de la responsabilidad jurídica (Análisis de la relación entre libertad y responsabilidad)», Anuario de la Facultad de Derecho de la Universidad Autónoma de Madrid, 4: 57-137.

NinO, C. S., 1980: Los limites de la responsabilidad penal. Una teoría liberal del delito, Buenos Aires: Astrea.

PetTit, P., 2002: «The Capacity to Have Done Otherwise», en Rules, Reasons, and Norms: Selected Essays, Oxford: Oxford University Press, 257-272.

Platón: Protágoras. Citado por la traducción castellana de J. CALONGe, E. Lledó y C. GarCía GuAL, 1981: Diálogos, vol. I, Madrid: Gredos.

RAWls, J., 1971: A Theory of Justice. Traducción castellana de M. D. GonZÁLEZ, 1979: Teoría de la justicia, México: FCE.

SAPOLSKY, R. M., 2004: «The Frontal Cortex and the Criminal Justice System», en S. ZeKI y O. GoOdenouch (eds.), Law and the Brain, Oxford: Oxford University Press, 227-244. 
SHichor, D., 2006: The Meaning and Nature of Punishment, Long Grove: Waveland Press.

STRAWSON, P. F., 1962: «Freedom and Resentment», en Freedom and Resentment and Other Essays, London: Methuen, 1974. Traducción castellana de J. J. ACERO, 1995: «Libertad y resentimiento», en Libertad y resentimiento y otros ensayos, Barcelona: Paidós, 37-68.

Ten, C. L., 1987: Crime, Guilt and Punishment, Oxford: Clarendon Press.

VAn Inwagen, P., 1882: «The Incompatibility of Free Will and Determinism», en G. Watson (ed.), Free Will, New York: Oxford University Press, 46-58.

VilajosanA, J. M., 2007: Identificación y justificación del derecho, Madrid-Barcelona-Buenos Aires: Marcial Pons.

Von Wright, G. H., 1998: «Of Human Freedom», en In The Shadow of Descartes. Essays in the Philosophy of Mind, Dordrecht-Boston-London: Kluwer, 1-45.

Walker, N., 1991: Why Punish?, Oxford: Oxford University Press.

WeATHERFORD, R., 1991: The Implications of Determinism, London-New York: Routledge. 
